\title{
ATRIAL SEPTAL DEFECT IN THREE GENERATIONS
}

\author{
BY \\ G. HOWITT \\ From the University Department of Cardiology, Manchester Royal Infirmary \\ Received December 21, 1960
}

Congenital heart disease occurs in two or more members of a family more often than can be accounted for by chance. Campbell (1959) found the condition to occur less commonly in parent and child than in sibs, and it occurs much less frequently in three generations, but he had two such families in his series: in one the girl, her mother, and grandmother all had atrial septal defects; in the other the boy and mother had aortic stenosis and the grandfather was said to have had a similar heart condition but had not been examined.

\section{Details of The Family}

In this report a family is described where the grandmother, mother, and child all had proved atrial septal defects. There does not appear to be any similar family reported where the congenital

TABLE I

Clinical Findings and Investigations in Three Patients with Atrial Septal Defect

\begin{tabular}{|c|c|c|}
\hline Grandmother, aged 55 & Mother, aged 27 & Child, aged 6 \\
\hline $\begin{array}{l}\text { Cardiac impulse suggestive of en- } \\
\text { largement of both ventricles. } \\
\text { Harsh long systolic murmur maximal } \\
\text { at LSE well heard at apex. Short } \\
\text { tricuspid flow murmur. } \\
\text { B.P. } 130 / 80 \text {. }\end{array}$ & $\begin{array}{l}\text { Clinical examination } \\
\text { Typical of ostium secundum defect. }\end{array}$ & $\begin{array}{l}\text { Cardiac impulse suggestive of en- } \\
\text { largement of both ventricles. } \\
\text { Short rough systolic murmur over } \\
\text { whole præcordium. Short tricuspid } \\
\text { flow murmur. } \\
\text { B.P. } 85 / 50 \text {. }\end{array}$ \\
\hline $\begin{array}{l}\text { C.t.r. } 15 \cdot 5: 24 \mathrm{~cm} ., 65 \text { per cent } \\
\text { Enlargement of both ventricles and } \\
\text { of P.A. }\end{array}$ & $\begin{array}{l}\text { Fluoroscopy } \\
\text { C.t.r. } 15: 26 \cdot 5 \mathrm{~cm} ., 57 \text { per cent } \\
\text { Typical of ostium secundum defect. }\end{array}$ & $\begin{array}{l}\text { C.t.r. } 10: 18 \mathrm{~cm} ., 56 \text { per cent } \\
\text { Prominent P.A. and over-vascularized } \\
\text { lung fields. }\end{array}$ \\
\hline $\begin{array}{l}\mathrm{P}-\mathrm{R} \text { interval } 0.36 \mathrm{sec} \text {. } \\
\text { rSR in V1. QRS } 0.08 \mathrm{sec} \text {. } \\
\mathrm{S}-\mathrm{T} \text { depression and } \mathrm{T} \text { wave inver- } \\
\text { sion V1-6. } \\
\text { Electrical axis-normal. }\end{array}$ & $\begin{array}{l}\text { Electrocardiogram } \\
\mathrm{P}-\mathrm{R} \text { interval } 0.24 \mathrm{sec} \text {. } \\
\text { rSR in V1. QRS } 0.08 \mathrm{sec} \text {. } \\
\mathrm{S}-\mathrm{T} \text { depression and } \mathrm{T} \text { wave inver- } \\
\text { sion V1-6. } \\
\text { Electrical axis-normal. }\end{array}$ & $\begin{array}{l}\text { QRS normal. } \\
\text { T wave inverted V1-V5. } \\
\text { Electrical axis-normal. }\end{array}$ \\
\hline $\begin{array}{l}\text { P.A.P. } 22 / 7 \text {; mean } 12 \\
\text { R.V. pressure } 37 / 0 \\
\text { Shunt through ASD } \\
\text { Systemic flow } 3 \cdot 5 \mathrm{~L} / \mathrm{M} \\
\text { Pulmonary flow } 15 \cdot 6 \mathrm{~L} / \mathrm{M}\end{array}$ & $\begin{array}{l}\quad \text { Cardiac catheterization } \\
\text { P.A.P. } 21 / 8 ; \text { mean } 12 . \\
\text { R.V. pressure } 40 / 0 \\
\text { Shunt through ASD } \\
\text { Systemic flow } 4 \cdot 2 \mathrm{~L} / \mathrm{M} \\
\text { Pulmonary flow } 12 \cdot 9 \mathrm{~L} / \mathrm{M}\end{array}$ & $\begin{array}{l}\text { P.A.P. } 26 / 14 ; \text { mean } 20 \\
\text { R.V. pressure } 39 / 4 \\
\text { ASD catheterized } \\
\text { Systemic flow } 1 \cdot 3 \mathrm{~L} / \mathrm{M} \\
\text { Pulmonary flow } 3 \cdot 4 \mathrm{~L} / \mathrm{M} \\
\text { Left sided SVC }\end{array}$ \\
\hline
\end{tabular}


heart lesion has been fully investigated in all three generations. The important findings in these three patients are given in Table I and the family tree is shown in Fig. 1. In the propositus (the child: V, 1, Fig. 1) and the grandmother (III, 2, Fig. 1) the diagnosis was in doubt prior to catheterization: the clinical and radiological features in these two patients suggest that the defect is of the ostium primum type, whereas the mother (IV, 2, Fig. 1) most probably has an ostium secundum defect. Only the child has a left-sided superior vena cava. It is possible that the great grandfather (II, 4, Fig. 1) suffered from congenital heart disease but there are no means of obtaining more definite information on this point: he had suffered from heart disease all his life and had a tendency

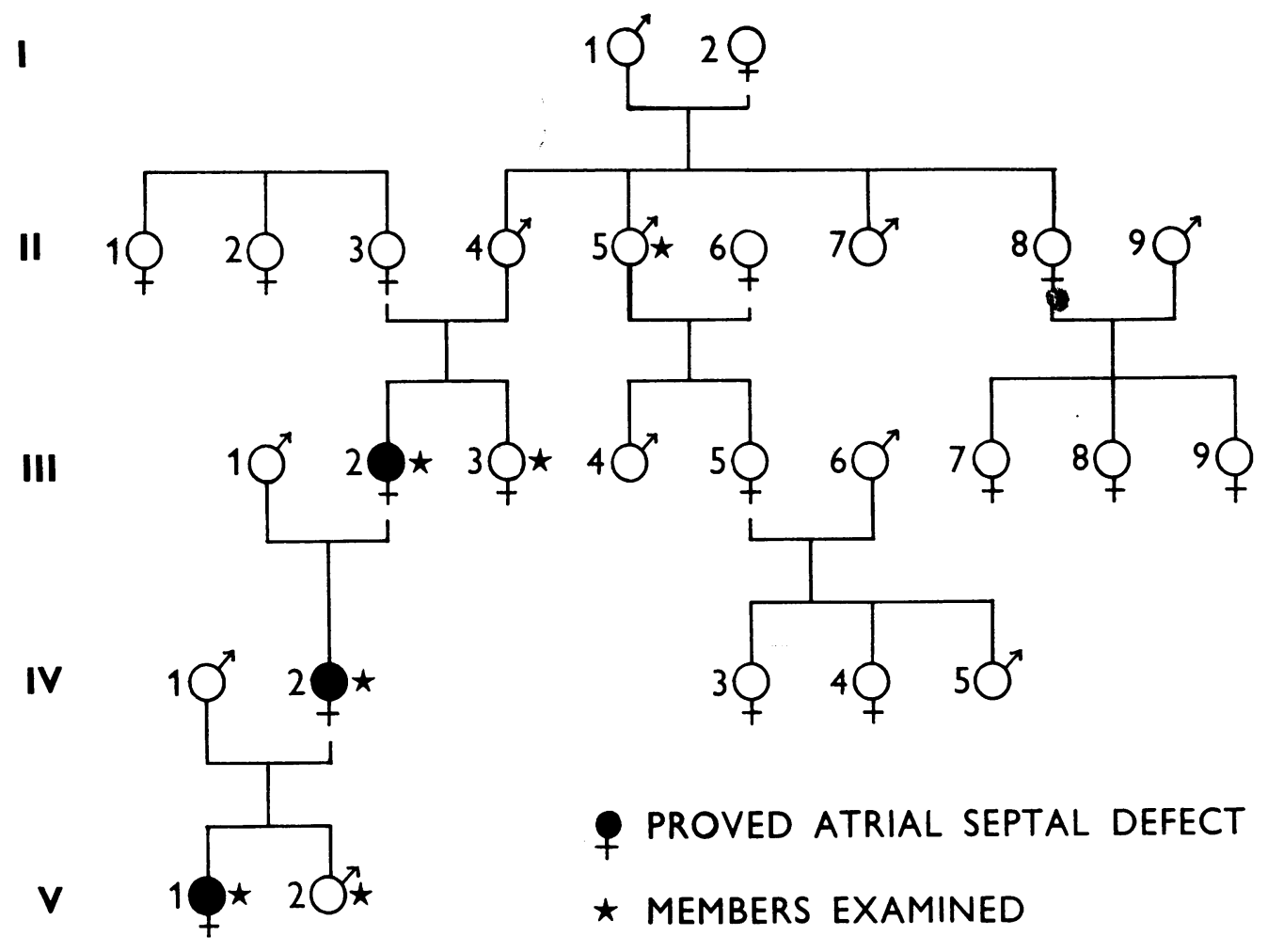

Fig. 1.-Family tree, showing a woman, her only daughter, and one of her two grandchildren, all with atrial septal defect. II 4 also may have been affected (see text).

to become cyanosed. He died at the age of forty and his death certificate (1919) states that death was due to "Pneumonia, mitral and aortic endocarditis, congestive heart failure." The great great grandmother (I, 2, Fig. 1) was said to be a sufferer from heart disease but she lived to the age of seventy-three. There was no history of heart disease in any other member of the family shown in Fig 1 and there were no consanguineous marriages.

\section{Discussion}

The factors responsible for multiple cases of congenital heart disease in a family have been discussed recently by Carleton et al. (1958), by Campbell, and in an annotation in the British Medical Journal (1959). Environmental causes, apart from rubella in pregnancy, have never been shown to play an important role and it seems most likely that genetic factors are responsible, although it is difficult to elucidate the actual mode of inheritance. Campbell states that although there is no decisive evidence, except in situs inversus, the general picture is compatible with recessive Mendelian inheritance. 
It is usual for the defects in a family to be of a similar nature and this has certainly been our experience. In the seven families we have investigated where there are two members affected, parent and child in three and sibs in four, the lesion has been the same or similar in each family.

There seems little doubt that in the family described here the cause is genetic and a strong probability in this particular instance is that the defect has been inherited as a Mendelian dominant.

\section{SUMMARY}

A family is described in which a woman, her daughter, and her grand-daughter all had atrial septal defect. In this family the defect appears to have been inherited as a Mendelian dominant character.

I wish to thank Sir Robert Platt for his advice, Dr. Morgan Jones and Dr. E. G. Wade for their help and permission to publish these cases, and the Department of Medical Illustration for the preparation of Fig. 1.

\section{REFERENCES}

British Medical Journal (1959). Annotation, 1, 704.

Campbell, M. (1959). Brit. Heart J., 21, 65.

Carleton, R. A., Abelman, W. H., and Hancock, E. W. (1958). New Engl. J. Med., 259, 1237. 